\title{
O Papel do BNDES nas Políticas de Desenvolvimento e Integração Regional
}

Le rôle du BNDES dans les politiques de développement et d'intégration régionale The role of the BNDES in the policies of regional development and integration El papel del BNDES en las políticas de desarrollo y integración regional

\section{Carla Hirt}

\section{OpenEdition}

\section{Journals}

Edição electrónica

URL: http://journals.openedition.org/espacoeconomia/423

DOI: 10.4000/espacoeconomia.423

ISSN: 2317-7837

\section{Editora}

Núcleo de Pesquisa Espaço \& Economia

Refêrencia eletrónica

Carla Hirt, «O Papel do BNDES nas Políticas de Desenvolvimento e Integração Regional », Espaço e Economia [Online], 3 | 2013, posto online no dia 19 dezembro 2013, consultado o 20 abril 2019. URL : http://journals.openedition.org/espacoeconomia/423; DOI : 10.4000/espacoeconomia.423

Este documento foi criado de forma automática no dia 20 Abril 2019.

(c) NUPEE 


\section{O Papel do BNDES nas Políticas de Desenvolvimento e Integração Regional}

Le rôle du BNDES dans les politiques de développement et d'intégration régionale The role of the BNDES in the policies of regional development and integration El papel del BNDES en las politicas de desarrollo y integración regional

\section{Carla Hirt}

\section{Introdução}

1 O BNDES é um banco estatal brasileiro que figura atualmente como uma das maiores agências de fomento do mundo. Criado durante o segundo governo de Getulio Vargas, o BNDE (ainda sem o Social) é instituição importante para entendermos os diferentes projetos de governo desde sua criação. Inicialmente os investimentos foram direcionados para a geração de infraestrutura, e aos poucos o banco passou a investir mais na iniciativa privada e na indústria. Na década de 1960 o setor agropecuário e as pequenas e médias empresas passaram a se beneficiar com linhas de financiamento do BNDE.

Em 1971 o BNDE tornou-se uma empresa pública de capital e direitos privados. Com isso o banco passou a ter maior liberdade nas operações de captação e aplicação de seus recursos. Os setores de bens de capital e insumos básicos passaram a receber mais investimentos nos anos 1970 - o que levou à formação do mais completo parque industrial da América Latina, em uma política de substituição de importações, e contribuiu para inserção do Brasil em um novo posto da Divisão Internacional do Trabalho. Em 1982 três subsidiárias do BNDE criadas em 1974 para atuar no mercado de capitais se fundiram e formaram a BNDESpar, de modo a ampliar as formas de capitalização das empresas brasileiras. Naquele ano o banco passou a chamar-se Banco Nacional de Desenvolvimento Econômico e Social (BNDES). Nos anos 1990, o BNDES teve papel importante na privatização das grandes estatais brasileiras, sendo o órgão responsável pelo suporte financeiro, administrativo e técnico do Programa Nacional de Desestatização, iniciado em 
1991. Este breve histórico ajuda-nos a conhecer um pouco dessa complexa empresa estatal brasileira. Contudo, esta pesquisa deve procurar entender o BNDES que temos atualmente, frente às recentes transformações na governança pública brasileira, e de que maneira essas mudanças foram impressas na atuação do banco. Estas são questões que pretendemos abordar ao longo deste trabalho.

3 É importante ressaltar que a base teórico-conceitual será apresentada ao longo do artigo, na medida em que isto se fizer necessário. Inicialmente contextualizamos o leitor no que diz respeito ao cenário em que o Banco atua.Nesse cenário, damos destaque à atuação do BNDES junto à IIRSA. Em seguida, discorremos sobre as fontes de recursos do banco e sobre como este atua utilizando recursos públicos brasileiros, de modo a justificar como entendemos que o conceito de desenvolvimento deve ser visto e quais são os principais sujeitos a serem priorizados para que esse desenvolvimento seja alcançado. Por último, serão apresentadas as reflexões finais.

\section{O cenário: a política e o território}

4 Para prosseguirmos na apresentação desta pesquisa, é necessário situarmos o leitor quanto ao contexto de algumas particularidades do sistema socioeconômico hegemônico (mas não homogêneo) em que estamos envolvidos. Este é o cenário principal, resultado de forças que competem e (re/des)organizam continuamente os territórios.

5 É necessário percebemos o capitalismo como articulador de uma pluralidade de unidades econômicas reciprocamente relacionadas. A base desse inter-relacionamento no nível do processo de elaboração são as condições gerais de produção (CGP $\left.{ }^{1}\right)$ do sistema capitalista. A "organização do sistema geral de ensino", "a extensão da medicina à generalidade da população", "medicina preventiva e vacinação", "esgotos e novas condições urbanas" etc (Vitte, 1979: 23-36) são exemplos de CGP. Estas "ultrapassam os limites de cada empresa particular e constituem uma vasta teia, sem a qual essas empresas e o próprio capitalismo não poderiam existir" (idem, 1979: 36). Um tipo específico de CGP que desperta mais nossa atenção nesta pesquisa diz respeito às condições gerais de existência física das empresas. Entre outras coisas, aqui se insere o que geralmente é considerado infraestrutura, como, por exemplo, as redes de produção, de distribuição de energia e de transportes (Bernardo, 1985).

6 A retórica estatal tem qualificado as obras de infraestrutura vinculadas à IIRSA (e ao Programa de Aceleração do Crescimento, no Brasil) como propulsoras do desenvolvimento sul-americano. Tal iniciativa teve suas origens na I Reunião de Presidentes da América do Sul, realizada em Brasília em agosto do ano 2000. Os líderes presentes à reunião acordaram em promover ações conjuntas em prol de um avanço nos processos de integração física, política, social e econômica da América do Sul. Tiveram destaque nos planos para essa integração a modernização da infraestrutura regional e outras medidas de caráter mais específico para promoção da integração e do desenvolvimento de regiões mais afastadas e isoladas (IIRSA, 2009a), segundo a retórica dos líderes políticos envolvidos nos projetos.

7 Contudo, muitos desses projetos têm sido duramente questionados por inúmeros sujeitos que declaram que tais obras de infraestrutura, da maneira como foram planejadas, vão dar continuidade ao processo de espoliação sofrido durante anos pelo continente sulamericano, tendo em vista o impacto territorial local e as ações ou sujeitos que serão 
beneficiados com a execução e conclusão das obras. Esse processo de espoliação seria um indício dos interesses do Estado Amplo, que se caracteriza como "tão lato quanto as próprias classes dominantes" e tem suas funções executadas pela classe gestora (ibidem, p. 92) - legitimado pelas ações do Estado Restrito. O BNDES vem atuando no âmbito da IIRSA fomentando grandes obras de infraestrutura nas quais, preferencialmente, grandes empreiteiras brasileiras estão envolvidas. Este é um sinal de que, como se pode ler na página do Banco na internet, o BNDES tem promovido a internacionalização de empresas brasileiras. Mais adiante veremos que as condições desses empréstimos e financiamentos não são necessariamente positivas para as contas públicas brasileiras, e que os eixos de interligação das obras de infraestrutura promovem a facilitação do escoamento da produção majoritariamente de matérias-primas.

Figura 1 : Eixos de integração e desenvolvimento (EID) da IIRSA

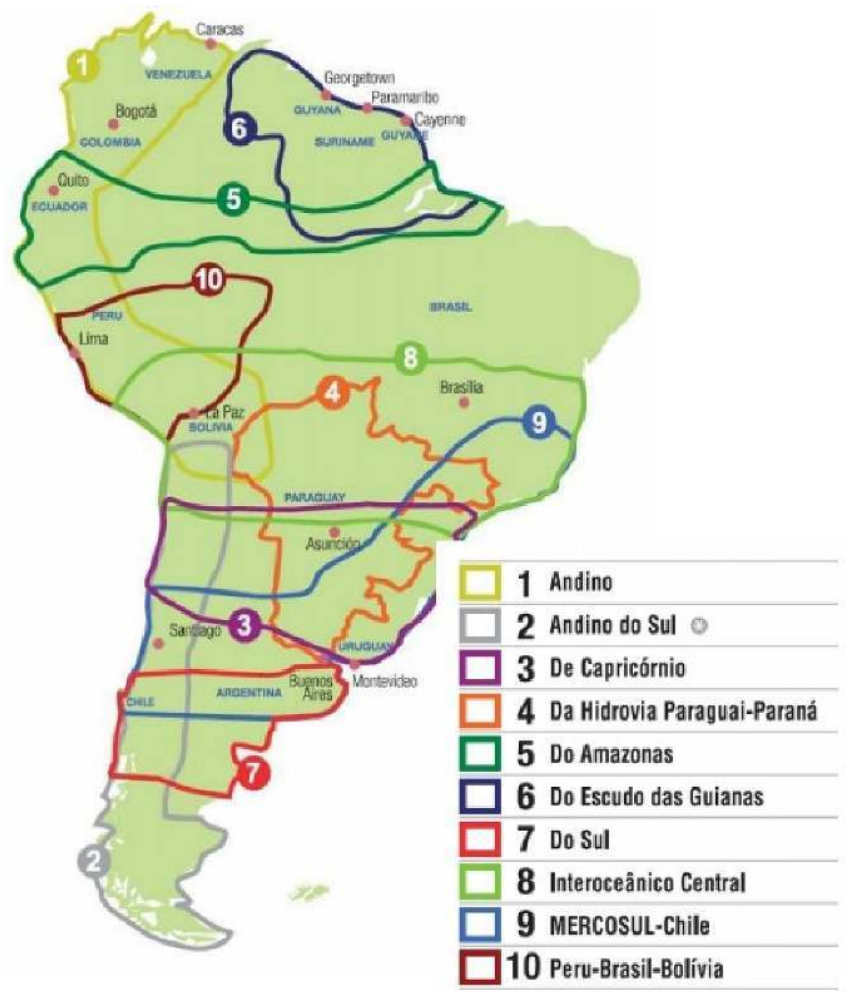

Fonte: Ministério das Relações Exteriores

8 As empresas são elementos constitutivos do Estado Amplo. Em sentido estritamente político, as empresas dizem respeito aos órgãos do Estado Amplo, e este se refere ao funcionamento das empresas como aparelho de poder. $\mathrm{O}$ capitalismo tem-se organizado em nível mundial em modalidades do Estado Restrito com o Estado Amplo. O Estado Restrito é, por definição, nacional, enquanto a concentração do capital transnacionalizou o Estado Amplo. Assim, os Estados Restritos já não têm qualquer possibilidade de se contraporem ao Estado Amplo, que conquistou uma indisputada margem de manobra (Bernardo, 1998:42-5).

9 As obras de infraestrutura previstas pela IIRSA, relacionadas com os corredores de exportação, foram definidas para as áreas de maior incidência de recursos estratégicos, e parece não se proporem, necessariamente, a favorecer as populações locais. Segundo os acordos da IIRSA, os governos financiarão $62,3 \%$ dos projetos, a iniciativa privada bancará 
20,9\%, enquanto o restante virá de instituições financeiras, como o BID, a Corporação Andina de Fomento (CAF) e o Banco Nacional de Desenvolvimento Econômico e Social (BNDES). Ou seja, há o risco de a dívida externa dos países sul-americanos crescer. Não esqueçamos que a dívida, mais que uma questão meramente financeira, é um instrumento político, pois garante a implementação dos interesses das instituições financeiras multilaterais, das grandes corporações, e de empresas transnacionais, à custa do endividamento público.

10 A primeira etapa da IIRSA consiste em um conjunto de 31 projetos estratégicos que causam impacto na integração física sul-americana. Esse conjunto de projetos foi aprovado pelo Comitê de Direção Executiva da IIRSA em 2004 (IIRSA, 2009a)., Tendo recebido atenção especial dos governos, essa primeira etapa de projetos teve um custo estimado em US\$ 10 bilhões e já se encontra em 14.023 bilhões. Em sua totalidade a IIRSA prevê 510 projetos, a um custo de US\$ 74,5 bilhões (IIRSA, 2009c).

11 Grandes empresas privadas brasileiras estão espraiando sua atuação por diversos países graças à atuação conjunta com o BNDES, que fomenta grande parte das obras de infraestrutura, do projeto supracitado e de outros projetos. Essa ação conjunta pode ser um indício de como este banco público se coloca a serviço de interesses de grupos econômicos privados brasileiros fora das fronteiras nacionais (Carrion \& Paim, 2006).

12 A uma visão pragmática, as empresas brasileiras desfrutam da vantagem de contar com o apoio do BNDES, e esse apoio as beneficia nas licitações para implementação dos projetos da IIRSA. Para Antônio José Cerqueira Antunes, ${ }^{2}$ ações empresariais brasileiras em outros países são de interesse nacional porque contribuem positivamente para o desenvolvimento econômico e para o fortalecimento da posição geopolítica do Brasil" (Antunes, $2007:$ 13-14).

13 Contudo, a transnacionalização do capital de empresas privadas brasileiras com o apoio estatal é um indício das políticas neoliberais governamentais. Além disso, a terra, o ar, as florestas e a água são ativos confiados ao Estado pelas pessoas a quem ele representa. Apossar-se desses ativos, privatizá-los, vendê-los ou facilitar a sua espoliação como se fossem parte do estoque de uma empresa privada constitui um processo de despossessão bárbara (Harvey, 2003 :133), que parece estar sendo financiado pelo Estado brasileiro. Esta afirmação se justifica pelo fato de que os 10 eixos da IIRSA visam à exploração do território e à facilitação da escoação para exportação. Isto, em vários casos, está subvertendo a ordem de muitos locais, que passam a ser explorados de acordo com as perspectivas do mercado internacional e das grandes corporações. Seria esse processo de espoliação (seja de quem for, beneficie quem quer que seja) a moeda de troca para o que alguns chamam de desenvolvimento econômico e para o fortalecimento da posição geopolítica do Brasil?

Procurando ter maior segurança ao discutirmos a problemática desta pesquisa, é importante deixarmos claro o modo como entendemos alguns conceitos adotados e também as categorias de análise empregadas. Optamos por fazer tais definições ao longo da exposição acerca do tema de pesquisa, de forma a contextualizar os conceitos em nossa análise, facilitando a compreensão do leitor. 


\section{O Estado, o BNDES e os territórios}

15 Esta pesquisa partirá do recorte espacial sul-americano, para entendermos o papel do BNDES na expansão dos interesses do Estado brasileiro para fora de suas fronteiras. É importante destacarmos que, ao nos referirmos ao Estado brasileiro, estamos considerando todos os poderes envolvidos, de acordo com a análise de João Bernardo (1996 e 1991) sobre os conceitos de Estado Amplo e Estado Restrito, citados anteriormente.

Em estreita relação com o modo como as pessoas usam a terra, como elas se organizam no espaço e como elas dão sentido ao lugar, estudaremos a territorialidade considerando também sua mudança de caráter em relação ao tempo (Sack, 1986). Essas relações mudam justamente pelo caráter constante de totalização do espaço geográfico (Santos, 1996).

17 Entendemos territorialidade como a tentativa - por diferentes sujeitos -- "de afetar, influenciar ou controlar pessoas, fenômenos e relações, através da delimitação e da afirmação de controle sobre uma área geográfica" (Sack, 1986 :32), sendo o território a área em questão.

18 A expansão de redes de infraestrutura de acordo com a lógica hegemônica parece ser um indício da territorialidade do Estado Amplo na América do Sul, através da IIRSA.

Segundo matéria publicada na Folha de S. Paulo, entre os anos de 2002 e 2009 o valor liberado pelo BNDES para investimentos na América Latina foi multiplicado por 3.000\%:

Com a crescente internacionalização das empresas brasileiras e o aumento da concorrência com os asiáticos nos países vizinhos, a linha do programa BNDES-Exim para o setor saltou de US\$ 42 milhões em 2002 para uma estimativa de US\$1,26 bilhão neste ano, dos quais US\$ 957 milhões já foram liberados até o mês passado. [...] Segundo levantamento da consultoria Valora, o Brasil exportou US\$ 5,673 bilhões em serviços de engenharia para os países latino-americanos em 2008, que representam uma participação de $50 \%$ a $60 \%$ do mercado regional. A presença brasileira ocorre principalmente nas obras de infraestrutura de geração de energia, transportes e saneamento (FSP, 27/9/2009, Caderno Dinheiro, B6).

20 Segundo a RedeBrasil, o BNDES estabeleceu relações estratégicas com a Corporación Andina de Fomento (CAF), que objetiva apoiar o desenvolvimento e a integração física dos países membros da IIRSA. O BNDES e a CAF assinaram em 2005 um memorando de atuação conjunta para co-financiar projetos em 17 países da América do Sul e do Caribe. Esta parceria se revela estratégica para alavancar projetos de infraestrutura (energia, transportes, hidrovias) no âmbito da IIRSA (ver www.rbrasil.org.br).

21 Nas últimas décadas tem aumentado a demanda por terras para o agronegócio. Contudo, a efetiva diminuição dos preços dos produtos agrícolas deu-se pela expansão do latifúndio, capital intensive, e pela anulação da renda diferencial por localização, possibilitada pela expansão das redes de transportes e pelos avanços da logística ( Porto-Gonçalves, 2006). Assim, a incorporação de grandes extensões de terras, principalmente para a produção de grãos, é fundamental para as grandes empresas de agronegócio.

A melhoria e a expansão da infraestrutura previstas na IIRSA são de interesse do Estado brasileiro. Tais obras possibilitam a consolidação de um novo mercado para as construtoras brasileiras, além de as grandes empresas passarem a contar com os mercados dos países sul-americanos para escoamento de seus produtos industriais, 
energéticos e do agronegócio e, em contrapartida, permitirem aos demais países acesso ao significativo mercado brasileiro (cf. Antunes, 2007:27-28).

Alguns exemplos de projetos da IIRSA executados por empreiteiras brasileiras são as obras da Usina Hidrelétrica Porce III, a $147 \mathrm{~km}$ da cidade de Medellín, na Colômbia, realizadas pela empresa Construções e Comércio Camargo Corrêa, ao valor estimado, em 2005 , de US $\$ 450$ milhões. Concluída em dezembro de 2010, a obra teve um custo total de US\$ 900 milhões. Segundo dados de 2005, a Camargo Corrêa atuava no exterior sob contratos que somam cerca de US\$900 milhões, o mesmo valor que custou apenas uma de suas obras, após reajustes nos custos, em 2010. No Peru, em 2004, a empresa firmou contrato para recuperação de um trecho de $60 \mathrm{~km}$ da estrada que liga Chiclayo a Chongoyape, no norte do país. Outra obra em execução é a construção de um trecho da estrada Inambari-Azangaro, com $305 \mathrm{~km}$ de extensão. Essa estrada faz parte da ligação oceânica entre Brasil e Peru. No mesmo ano a empresa assinou, na Bolívia, contrato para construção da rodovia Roboré-El Carmen, de $140 \mathrm{~km}$, parte de um corredor interoceânico que permitirá a saída da Bolívia para o Pacífico e ligará as cidades Santa Cruz de la Sierra e Puerto Suarez. O Corredor Viário Interoceânico Sul - Peru/Brasil, entre Peru, Bolívia e Brasil, é dividido em cinco trechos: três são construídos pela Odebrecht com sócios peruanos; um é executado pela peruana Hidalgo e Hidalgo SAC; e o quarto trecho é feito pela Intersur Concesiones SAC, formada pelas brasileiras Camargo Correa, Andrade Gutiérrez e Queiroz Galvão. O preço da obra, orçado inicialmente em US\$ 527 milhões, subiu para US\$ 890 milhões após a Intersur Concesiones SAC ter sido aprovada. Durante a construção do trecho 4 da rodovia, que interliga Inambari (Madre de Dios) e Azangaro (Puno), inúmeras foram as denúncias de irregularidades no que diz respeito ao cuidado técnico e humano e de proteção ao patrimônio arqueológico (Ugaz, 2009).

$O$ apoio do BNDES à exportação dos serviços de engenharia é uma operação de dimensão estratégica. Segundo alguns autores, esses projetos geram empregos "ao longo de uma diversificada cadeia produtiva nacional, intensiva em tecnologia e em conhecimento, sobretudo por integrarem tais cadeias em escala regional" (SANTOS, F. 2006:6). Para Santos (2006), o modelo institucional de garantias mútuas viabiliza empreendimentos de alta complexidade e alto valor agregado, como são também os casos de diversas operações de empréstimo do BNDES.

Assim, com o apoio do BNDES o governo brasileiro procura ter uma política de exportação integrada, incorporando o setor de serviços de maneira mais agressiva e procurando ter uma atuação competitiva em um cenário de tentativas crescentes de regulamentação do comércio mundial e de crescimento das exportações das commodities.

Contudo, diversas organizações da sociedade civil pressionam por maior interlocução com o Banco, pressionando por maior transparência nas ações e pelo uso dos recursos com enfoque social.

É comum ouvirmos a crítica de que o $\mathrm{S}$ do BNDES é figurativo, já que está longe de chegar a $10 \%$ do desembolso total do Banco. Só que a dimensão social do BNDES precisa extrapolar a área destinada à realização de projetos sociais e necessita estar presente em cada projeto de investimento, como estratégia para induzir a diminuição das desigualdades de toda ordem. Por entendermos que o alcance e o impacto dos empréstimos do BNDES vão além de seus beneficiários diretos, atingindo positiva e negativamente a sociedade como um todo, acreditamos que a construção de espaços institucionais de interlocução entre a sociedade civil e o Banco, para se discutirem as prioridades e diretrizes, é fundamental. Somente um diálogo franco e público com essas organizações da sociedade civil, que expresse o 
avanço político da sociedade brasileira nas últimas décadas, poderá levar o $\mathrm{S}$ da sigla do Banco a verdadeiramente traduzir a dimensão social que precisam ter quaisquer financiamentos de empresas públicas no século 21. Não faltam oportunidades e razões para esse diálogo. Se até hoje o Banco relacionou-se apenas com o setor produtivo, cabe agora um repensar a sua atuação e reconhecer que o desenvolvimento só tem sentido caso sirva para radicalizar a cidadania e distribuir, entre todos os cidadãos e cidadãs, as benesses do desenvolvimento (cf.www.ibase.br/conteudos/por_que_fazer.htm, 2008). participação nas decisões do Banco. Outro exemplo é a Plataforma BNDES ${ }^{3}$, que atua de modo a pressionar pela democratização do maior instrumento de desenvolvimento do Brasil, o BNDES. Em agosto de 2011, a Plataforma BNDES protocolou uma carta de apoio às populações do território indígena e parque nacional Isiboro Sécure - Tipnis, Bolívia. A carta foi endereçada ao presidente do Banco, Luciano Coutinho, e pede imediata suspensão do financiamento do projeto de construção de uma estrada que pretende ligar as localidades de Villa Tunari e San Ignacio de Moxos, na Bolívia. "Entendemos que esse financiamento, concedido no âmbito do contrato de cooperação financeira celebrado entre o BNDES e o governo da Bolívia, viola inúmeros direitos dos bolivianos e compromete a convivência harmoniosa entre os povos do Brasil e da Bolívia." função de obras de infraestrutura conduzidas com apoio do BNDES - que nitidamente se posiciona de acordo com a lógica hegemônica do capitalismo, pela conquista de mercados e pela internacionalização de grandes empresas brasileiras.

No que diz respeito ao grau de internacionalização, os grupos econômicos brasileiros mais significativos são: Gerdau, Construtora Norberto Odebrecht, CVRD, Petrobras, Marcopolo, Sabó, Aracruz, Klabin, Sadia, Perdigão, Embraer, Natura, Votorantim e Andrade Gutierrez. (Vitte, 2009 :8). Estes grupos têm interesses na ampliação da infraestrutura na América do Sul e em melhorias no escoamento de seus produtos para os portos do Atlântico e do Pacífico. A Odebrecht, a Camargo Correa e a Andrade Gutierrez se constituíram como holdings e diversificaram seus negócios.

Além da área de engenharia, a Odebrecht é o maior grupo petroquímico da América ao controlar a empresa Braskem, e prevê investimentos bilionários nos próximos anos em sua subsidiária ETH Bioenergia, voltada para a produção de etanol da canade-açúcar. Já a Camargo Correa tem sua própria fábrica de cimento e controla a Alpargatas Calçados (Havaianas, Rainha, Topper, Timberland e Mizuno), é acionista da Siderúrgica Usiminas, da concessionária de energia do estado de São Paulo CPFL Energia e ainda da Companhia de Concessões Rodoviárias (CCR), controladora da Dutra (RJ-SP) e no Paraná, totalizando $1.452 \mathrm{~km}$ em concessões rodoviárias. A Andrade Gutierrez não fica atrás: também é acionista da concessionária CCR; da prestadora de serviços de energia Light; controla a empresa de telecomunicações Telemar (que engloba também a OI celulares) e terá a concessão do aeroporto de Quito, no Equador, ainda em construção. Expor esses extensos dados é fundamental para que os atores sociais brasileiros tenham dimensão do poder econômico dessas empresas transnacionais de base brasileira [...]. Essa configuração altamente concentradora de capital permite a esses grupos pautar políticas públicas e competir internacionalmente a custos mais baixos no que concerne às grandes obras, em que o repasse de recursos públicos é por vezes burocrático e tardio (Couto, 2008: 82-83).

Sobre os conflitos entre os agentes em vários dos eixos da IIRSA, não é a logística o maior problema para manter a expansão da produção do cultivo da soja (e de outros produtos). 
O conflito central reside na questão sociopolítica e territorial. O território é um espaço definido e delimitado por e a partir de relações de poder. O poder, por sua vez, não se restringe ao Estado e não se confunde com violência e dominação (Souza, 2001). Partindo deste pressuposto, o conceito de território abarca mais que o território dos EstadosNação; engloba também as correlações de poder, por mais desiguais que sejam, e estas devem ser estudadas para que se alcancemas necessidades dos diferentes sujeitos que (trans)formam as porções do espaço geográfico em questão. No caminho dos eixos previstos pela IIRSA (e também pelo PAC, no Brasil) existem espaços-tempos diferentes e em disputa. $O$ espaço-tempo das corporações consiste na associação da logística com a geopolítica, expandindo velozmente a produção e as redes de controle e escoamento, realizando alianças com governos e outras empresas para atingirem seus objetivos. Já o espaço-tempo dos produtores familiares, dos indígenas e de populações tradicionais não conta com meios técnicos e financeiros; realiza-se com uma temporalidade diferente, incorpora de forma mais lenta as mudanças, e esses grupos almejam manter suas terras e sua identidade. São, assim, territorialidades que conflitam.

\section{Sobre desenvolvimento}

31 Para entendermos o impacto territorial de que trata a pesquisa, devemos antes nos perguntar: de qual desenvolvimento estamos falando? Nossa base é a perspectiva de que crescimento e modernização devem valer como indicadores de desenvolvimento se forem acompanhados de distribuição da riqueza socialmente produzida e atendimento de necessidades materiais e imateriais elementares (Souza, 1996 :7). Assim, parece-nos importante não dissociarmos razão, emoção, afetividade, e outros elementos que compõem toda a complexidade que nos cerca. A ciência moderna possibilitou que as tomadas de decisões do Estado se realizassem a partir de uma retórica legitimadora, dita "racional". O princípio da verdade proporcionado por esta ciência da racionalidade foi a base para que muitas das tomadas de decisões fossem interpretadas automaticamente como corretas, uma vez que o entendido como verdadeiro conduzia ao bem (como se a verdade fosse algo unidimensional e não passível de interpretações).

Pelo fato de a racionalidade ter se tornado há muito tempo sinônimo de "racionalidade científica", e o conhecimento, sinônimo de "conhecimento científico", outras formas de conhecimento e outros recursos para a racionalidade e conhecimento prático da agricultura, da medicina ou de artesanato foram considerados de segunda classe, e desconsiderados (Funtowicz e de Marchi, 2000 apud Porto-Gonçalves, 2002 : 218).

Assim, para discutirmos desenvolvimento, temos que observar os paradigmas em questão. Inúmeros são os casos de conflitos resultantes dos impactos territoriais surgidos a partir do planejamento (ou apoio) estatal embasado em paradigmas reducionistas, que se confrontam com as necessidades reais das populações atingidas. É importante, pois, considerarmos os diferentes paradigmas, as diferentes éticas e as diferentes motivações dos sujeitos envolvidos. Esta é uma possibilidade que "mostra-nos um mundo muito mais diverso do que faz crer o olhar colonial eurocêntrico ou que vê mais a lógica do capital do que as lógicas dos que a ele resistem" (Porto-Gonçalves, $2002: 220$ ). As racionalidades tecidas a partir de diferentes modos de sentir, agir, pensar e interpretar têm destaque nesta pesquisa devido à emergência da necessidade de se (re)interpretar e (des)orientar os atuais ordenamentos territoriais que, da maneira como têm sido planejados e executados, parecem resultar em conhecidos problemas que prejudicaram o 
desenvolvimento: o processo de acumulação por espoliação - em alguns (não raros) casos financiado e orquestrado pelo próprio Estado.

\section{Reflexões finais}

Ao investir em modelos causadores de desigualdades, em vez de estimular a diversificação e a integração produtiva entre os países sul-americanos, o BNDES, através da IIRSA, parece propor um modelo de atuação que agrava o processo de reprimarização das economias voltado para a produção e exportação de commodities. Esse modelo beneficia grandes corporações, aprofunda a histórica espoliação sofrida pelos povos sulamericanos, e coloca em risco o meio ambiente e as populações atingidas (especialmente suas camadas menos privilegiadas). Assim procedendo, o BNDES parece posicionar-se a favor da inclusão no sistema de espoliação e acumulação capitalista das áreas da América do Sul ainda não englobadas e organizadas por tal lógica hegemônica de (des)organização de territórios, atuando também em nome da ampliação da atuação de empresas brasileiras no exterior e da facilitação do acesso dos mercados consumidores de outros países aos bens manufaturados do Brasil.

Entendemos que um banco que se utiliza de recursos públicos deve priorizar a população e ser democrático no que diz respeito aos seus processos decisórios. O que se observa atualmente é que o BNDES não é um banco democrático, se observarmos que se trata de uma instituição pública que não possui um meio de consulta franqueado à sociedade e não permite que esta tenha voz em suas decisões. Na página do Banco na internet está posto que, "na condição de empresa pública, o BNDES adota o princípio da ampla transparência como um dos pilares de seu relacionamento com os atores externos", e que "a fim de manter aberto seu canal de comunicação com a sociedade, o Banco fornece à mídia, regularmente, notícias a respeito de suas atividades, por meio da divulgação de pressreleases sobre operações de financiamento, política e prática de crédito" Vê-se, assim, que a sua retórica vai na direção da transparência e da comunicação.

Contudo, entendemos que uma empresa pública que recorre aos fundos públicos deve manter uma comunicação eficiente com os cidadãos, pela qual a sociedade tenha voz e seja ouvida - o que, na verdade, não acontece. A sociedade civil, mesmo se organizando em movimentos sociais, não consegue estabelecer um diálogo aberto e constante com o Banco. Ao que tudo indica, porém, as grandes empresas brasileiras conseguem dialogar e influir nas tomadas de decisões não só do BNDES, mas do Governo brasileiro. A partir da análise desses pontos fundamentais, entendemos que o papel que o BNDES desempenha nas políticas de desenvolvimento e Integração Regional é de facilitador da concentração de capital, através do financiamento de obras que atendem aos interesses das grandes empresas de capital privado brasileiro, mesmo que isso implique um impacto drástico na escala local para povos que acabam tendo seus territórios desorganizados, em um processo de despossessão bárbaro. 


\section{BIBLIOGRAPHY}

ANTUNES, A. J. C. Infraestrutura na América do Sul: situação atual, necessidades e complementaridades possíveis com o Brasil. Brasília: Cepal, LC/BRS/R.186, setembro, 2007.

BERNARDO, J. Estado. A silenciosa multiplicação do poder. São Paulo: Escrituras, 1998.

BERNARDO, J. Economia dos conflitos sociais. São Paulo: Cortez, 1991.

COUTO, A. B. A atuação das grandes empreiteiras brasileiras na integração de infraestrutura na América do Sul. In: VERDUN, Ricardo et al. (orgs.). Financiamento e megaprojetos: uma interpretação da dinâmica regional sul-americana. Brasília: Inesc, 2008.

PORTO-GONÇALVES, C. W. A globalização da natureza e a natureza da globalização. Rio de Janeiro: Civilização Brasileira, 2006.

SACK, R. D. Human territoriality.Its theory and history.Cambridge: University Press, 1986.

SOUZA, M. L. "Território" da divergência (e da confusão): em torno das imprecisas fronteiras de um conceito fundamental. In: SAQUET, M. A.. e SPOSITO, E. S. (orgs.). Território e territorialidades: teorias, processos e conflitos. São Paulo: Expressão Popular: Enesp. Programa de Pós-Graduação em Geografia, 2009, 368 p.

BRASIL, MINISTÉRIO DAS RELAÇÕES EXTERIORES. Os projetos de infraestrutura apoiados pelo Brasil na América do Sul. 2011. In: http://www.fiesp.com.br/irs/cos-cex/pdf/

transparencias_reuniao_coscex_09_08_11_-_ministro_joao_mendes.pdf .

CARRION, M. C. \& PAIM, E. S. IIRSA: Desvendando interesses. Porto Alegre: Amigos da Terra, fevereiro de 2006. In: www. natbrasil.org. Acesso em 9/9/2010.

IIRSA. Agenda de Implementação Consensual 2004-2010. Disponível em: <http://www.iirsa.org/ BancoConocimiento/A/agenda_de_implementacion_consensuad a_2005 -2010/ agenda_de_implementacion_consensuada_2005-2010.asp?CodIdio-ma=ESP> . Acesso em: 24/11/2009a.

REDE BRASIL. BID: $O$ banco da ALCA? Brasília: RedeBrasil. Informe n. 17, ago. 2004. Disponível em: www.rbrasil.org.br. Acesso em 20/9/2011.

SANTOS, F. Democracia, Legislativo e os novos desafios para a expansão do capitalismo brasileiro. Observatório Político Sul-americano. Iuperj/UCAM, setembro de 2006. In: www.observatorio.iuperj.br. Acesso em 21/12/2008.

UCHOAS, L. Projetos financiados pelo BNDES causam danos sociais e ambientais. In: http:// www.brasildefato.com.br/v01/agencia/especiais/especial-bndes/projetos-financiados-pelobndes-causam-danos-sociais-e-ambientais/. Acesso em 8/4/2010.

UGAZ, P. Consórcio com Camargo Correa é questionado no Peru. Revista eletrônica Terra Magazine de 6/4/2009. In: http://terramagazine.terra.com.br/interna/0,OI3687921EI6578,00Consorcio+com +Ca-margo+Correa+e+questionado+no+Peru.html. Acesso em 8/9/2010.

VITTE, C. C. S.. Planejamento territorial e os impactos socioeconômicos da IIRSA (Iniciativa de Integração da Infraestrutura Regional Sul-Americana) no território brasileiro: atores, conflitos e interesses. In: http://egal2009.easyplanners.info/area01/1022_Claudete_Vitte.pdf .p. 1-17. 


\section{NOTES}

1. Produção entendida no seu sentido social, uma vez que vai muito além da materialidade, sendo uma produção social complexa.

2. Secretário de Programas Regionais Integrados do Ministério da Integração Nacional em 2001.

3. Grupo significativo de organizações e movimentos populares que se reuniu no ano de 2007 para formar uma frente ampla em prol da democratização de um dos instrumentos de promoção do desenvolvimento nacional: o BNDES.

\section{ABSTRACTS}

Nosso artigo visa problematizar as políticas de desenvolvimento financiadas através de parcerias entre o setor privado e o Banco Nacional de Desenvolvimento Econômico e Social (BNDES) e suas implicações territoriais. Buscamos estudar os impactos geográficos dos empreendimentos realizados no âmbito da Iniciativa para a Integração da Infraestrutura Regional Sul-americana (IIRSA), através de empréstimos e financiamentos realizados junto ao BNDES. Em termos metodológicos, avaliaremos qualitativamente dados levantados por meio de documentos fornecidos pela Plataforma BNDES, bem como relatos documentados de populações que se dizem impactadas por projetos financiados pelo mesmo. 0 recorte espacial desta pesquisa é a América do Sul, região de forte atuação do BNDES nos últimos anos pelo fato deste banco ser uma das mas maiores agências de fomento da IIRSA. As principais categorias geográficas de análise abordadas são: território, territorialidade e redes.

Cet article vise à problématiser les politiques de développement financées par des partenariats entre le secteur privé et la Banque Nationale de Développement Économique et Social (BNDES) avec ses articulations territoriales. Nous cherchons d'étudier les impacts géographiques des œuvres réalisées dans le cadre de l'Initiative pour l'Intégration de l'Infrastructure Régionale SudAméricaine (IIRSA) à travers des emprunts et financements de la BNDES. Du point de vue méthodologique, nous allons évaluer qualitativement des données de la Plateforme BNDES, ainsi que les mémoires de populations qui se considèrent impactées par des projets ainsi financés. Cette recherche se déroule dans le cadre de l'Amérique du Sud, région de référence de la BNDES, en étant cette dernière est l'un des principaux bailleurs de fonds de l'IIRSA. Les catégories géographiques principales que nous mobilisons dans notre recherche sont: territoire, territorialité et réseaux.

This article aims to problematize the development policies founded in partnership by the private sector and the National Bank of Social and Economic Development (BNDES), with its territorial articulations. We wish to study the geographical impacts of works realized within the Initiative for the Integration of the Regional South-American Infrastructure (IIRSA) through BNDES loans and founding. On a methodological standpoint, we'll evaluate in a qualitative way data furnished by the BNDES Platform, as well as the documents furnished by populations which consider 
themselves as impacted by the founded projects. This research is developed in the frame of South America, which is the BNDES region of impact, because this bank is one of the main IIRSA financers. We mobilize as main geographical categories the concepts of territory, territoriality and networks.

Nuestro artículo tiene el objetivo de problematizar las políticas de desarrollo financiadas a través de las alianzas entre el sector privado y el Banco Nacional de Desarrollo Económico y Social (BNDES) y sus implicaciones territoriales. Buscamos estudiar los impactos geográficos de las inversiones realizadas en el ámbito de la Iniciativa para la Integración de la Infraestructura Regional Suramericana (IIRSA) mediante préstamos y financiamientos concedidos por el BNDES. En términos metodológicos, evaluaremos cualitativamente los datos levantados por medio de la Plataforma BNDES, así como los relatos documentados de las poblaciones que se asumen como afectadas por los proyectos financiados. El área espacial de esta investigación es América del Sur, región de fuerte actuación del BNDES en los últimos años ya que este banco es una de las mayores agencias de fomento de la IIRSA. Las principales categorías geográficas de análisis abordadas son: territorio, territorialidad y redes.

\section{INDEX}

Mots-clés: développement, intégration, territoire, IIRSA

Keywords: development, territory, BNDES

Palavras-chave: desenvolvimento, integração, território

Palabras claves: desarrollo, integración

\section{AUTHOR}

\section{CARLA HIRT}

Doutoranda em Planejamento Urbano e Regional no IPPUR/UFRJ. Professora do Departamento de Geografia da UERJ. Email: hirt.carla@gmail.com 